\title{
AUMC Infinity Predicted Normalized by Weight
}

National Cancer Institute

\section{Source}

National Cancer Institute. AUMC Infinity Predicted Normalized by Weight. NCI Thesaurus. Code C92337.

The area under the first moment curve (AUMC) extrapolated to infinity, based on the last predicted concentration divided by the weight. 